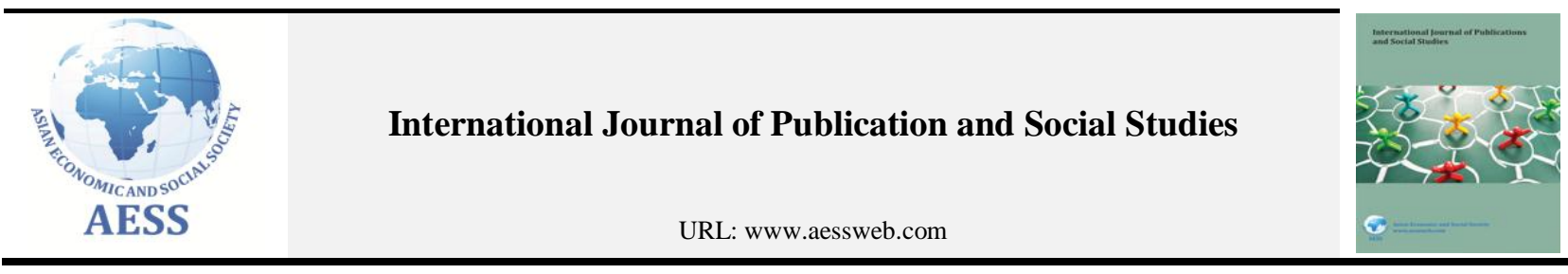

\title{
MULTICULTURAL PERSONALITY AND CROSS-CULTURAL ADJUSTMENT AMONG SOJOURNERS IN NEW ZEALAND ${ }^{1}$
}

\author{
Awang Rozaimi $^{1}+$--- Siti Huzaimah ${ }^{2}$--- Affidah Morni $^{3}$ \\ ${ }_{1,2,3}$ Universiti Teknologi MARA Sarawak, Samarahan Campus, Sarawak, Malaysia
}

\section{ABSTRACT}

Different parts of the world are offering sojourners with a variety of socio-cultural experiences. The inability to understand the variation triggers psychological, physical or behavioural difficulties, and maladjustment or misunderstanding. It is discovered that cross-cultural underestimation is the root of intercultural resistance, stereotyping, ethnocentrism and racism sentiments among sojourners. The online survey was conducted in the present study to comprehend the role of multicultural personality traits on sojourners' cross-cultural adjustment. With snowball method and a purposive sampling, 55.5\% of response rate was obtained among Malaysian sojourners in the New Zealand. Basically, the manifestation of self and other's affection, behavioural and contextual variations amplify the rationalisation and contradictory nature of cultural variation. Highlighted, social initiative is a sole important multicultural personality trait which perceived as vital to the success of sojourners' cross-cultural adjustment abroad. The implication of the study is discussed.

(C) 2017 AESS Publications. All Rights Reserved.

Keywords: International human resource development, Multicultural personality, Cross-cultural adjustment, Sojourners, Cultural variation, Social initiative.

Received: 13 October 2016/ Revised: 25 October 2016/ Accepted: 3 November 2016/ Published: 8 November 2016

\section{Contribution/ Originality}

This study contributes by giving further support on the use of shortened version of MPQ (MPQ-SV) and revised version of SCAS (SCAS-R). Additionally, the present study also gives additional understanding of the international mobility research by highlighting the importance of multicultural personality, especially social initiative trait on sojourners' cross-cultural adjustment.

\section{INTRODUCTION}

International mobility challenges a person's physical, psychological, socio-cultural and financial fitness. Sojourning success depends on sojourner's personal competencies in facing various political, economic and sociocultural challenges experienced overseas. The purpose of this exploratory study is to empirically observe the sociocultural influences on the sojourner's effective cross-cultural adjustment. In particular, cross-cultural adjustment refers to the successful adaptation and acculturation process which encompass the psychological and behavioural

\footnotetext{
${ }^{1}$ Early version of the paper has presented at the $6^{\text {th }}$ Asia Pacific Marketing and Management Conference (APMMC) 2016, 16-18 March 2016, Kuching, Sarawak, Malaysia.
} 
responses to ecological, socio-political and cultural context (Berry, 2010). It is a reflection on sojourner's affective, cognitive and behavioural discrepancy to signify the changes experienced in different socio-cultural environment (Ward and Kennedy, 1999). Sufficient rationalization and interactive adjustment are vital in reducing socio-cultural difficulties on sojourner's daily living, working and interacting with others' from the visited country. The present study is carried out through a survey to elicit sojourners' multicultural personality on their cross-cultural adjustment abroad.

Cross-cultural difficulties, ethnocentrism, racism and stereotyping problems occur due to misinterpretation of the rigorous spectrum nature of the culture. In order to prove a beneficial international mobility, sojourners entail to make essential adaptation by integrating a micro- and macro-cultural appealing, and react towards the differences and changes. Sojourners, described in the expatriation literature (Bhaskar-Shrinivas et al., 2005) are international travellers includes asylum seekers, expatriate managers, immigrants, missionaries, peacemakers, refugees, students, tourists and, visiting, high-skills or guest workers. Every international traveller is equipped with distinct cultural frame-of-references moulded in their home location since born. Those cultural variations experienced by sojourners are vary due to their international mobility destination, goals, lengths of stay and expectation. A study by Searle and Ward (1990) presented an empirical inclusion to the cross-cultural adjustment between Asian's (Malaysian and Singaporean) and New Zealand's socio-cultural context. Besides, multicultural personality is an individual ecological character that supports sojourners to produce a rational justification when embarking into socio-cultural discrepancies (Guyton and Wesche, 2005; Froese and Peltokorpi, 2011; Froese, 2012; Van et al., 2013). Theoretically, an acculturation disposition from the agricultural approach of Berry (2010) provides an effective cultural, environmental context facilitates socio-cultural understanding.

\subsection{Cross-Cultural Adjustment}

Encountering uncertain decision, significant adjustment and adaptation demanded a person to redefine his/her affective, cognitive and behavioural abilities appropriately. According to Ward and Kennedy (1999) the ability to 'fitin' into the distinct culture variation environment is crucial. It challenges a person's knowledge, understanding, experience and ability to negotiate physically and literally with all aspects hooked in their daily living, working and interaction with others. Dennis and Stroh (1993) shared a study of American expatriates, who reported that an education system, language, lifestyles, racial, religious, ethnic groups and organizations internal rivalries are the contributing factors in the work-family difficulties for sojourns in Kuala Lumpur. In addition, transportation preferences in Kuala Lumpur were found unfavourable, thus causing the expatriates' frustration (Butler and Hannam, 2014). Basically, cross-cultural adjustment and adaptation involve a process of changing the perception into appropriate manners which determine the sojourners' psychological and socio-cultural composing in holistic views.

Inability to establish meaningful cross-cultural adaptation and adjustment contributes to the sojourning difficulties which including a decreased in productivity, drop-out among students, premature return, insufficient organizational and social support, intention to leave, learning helplessness and frustration, perceived uneven marginalization and discrimination, strain and stress, turnover or failure, uncertainty in future career development, and unsatisfactory performance (Bhaskar-Shrinivas et al., 2005; Shaffer et al., 2012). In addition, communication breakdown, intercultural conflict and, spouse's involvement (Lauring and Selmer, 2010) and work-family conflict gives additional strain to the sojourners' international mobility. Discrepancy in international performance during sojourners' international mobility is believed to be depending on their coping strategy, cultural knowledge and background, life experience and maturity, motivation, personality and styles of learning whilst dealing with sociocultural uncertainty (Freeman and Lindsay, 2012; Froese, 2012; Harvey et al., 2012). Therefore, it does not merely concern in accomplishing assigned responsibility of an international assignment, but the ability to adapt and adjust appropriately in a socio-cultural atmosphere of foreign location which is essential in ensuring adequate sojourn mission. 


\subsection{Multicultural Personality}

A person's ecological wellbeing is shaped by the combination of characters which socially formed from his/her socio-cultural habitation (Berry, 2010). This habitual ecological conception is explained later in this paper. The ability of a person to adjust and adapt with different socio-cultural habitation depends on his/her anticipation with the social similarity and differences. The attitudinal elements or personality explains the way people act and perceive things according to their frame-of-preferences (Lee and Sukoco, 2007). Notably, personality plays a significant role for effective cross-cultural adjustment abroad.

However, a person's personality varies depending on their initial socio-cultural habitation. Character building is influenced by environmental factors which include family, society and national socio-cultural (attitude, belief, norm and values), economic and politic compositions. Thus, personality explains an individual's cognitive ability (recognition of similarities or differences), affective resonance (sense of connectedness) and behavioural (intent to behave) competently (Terracciano et al., 2003). Ability to interact with others with different cultural-related personality is challenged, especially while working and living in different socio-cultural atmosphere. Thus, scholars (Froese and Peltokorpi, 2011; Van et al., 2013) argued that cultural distance and culture-based personality are predecessors for sojourner's cross-cultural adjustment and job satisfaction abroad. Van et al. (2013) posited the multicultural personality manifested by five characters which includes: cultural empathy, emotional stability, flexibility, open-mindedness and social initiative. Firstly, willingness to adapt, sensitive to feelings and social norms, and recompense respect show individual ability of cultural empathy. Secondly, ability to suppress the emotion determines sojourner's emotional stability reducing cross-cultural difficulties. Thirdly, flexibility character allows sojourner's making necessary adjustment, which determine social acceptance by the others from different sociocultural habitation. Fourthly, unrestricted thought, feeling and behaviour allow open-mindedness, which help to regulate strains and stress while interacting with the others. Lastly, social initiative is essential to establish beneficial connectedness with the others while sojourning abroad.

\subsection{Ecological Approach}

It is undeniable that the practical socio-cultural knowledge and skills are fundamental to the effective adaptation and adjustment in overseas. Sufficient pre-departure preparation is important to ensure adjustment readiness among sojourners (and family members) as to meet the physical and psychological expectation in the host location. An awareness to the cultural cues (salient message related to a cultural attitude, belief, norms and values) becomes a foundation to face socio-cultural surprises (reality below expectation) and acculturate with cultural differences (Berry, 2010; Sam and Berry, 2010). As experienced by Friedman (2007) and Friedman et al. (2009) it is believed that the cultural history and the notion of the concept of Mianzi (face-saving) and guanxi (pride) among Chinese subordinates in Hong Kong aided expatriate to avoid social separations and, feelings of annoyance. Hence, international sojourning is not only about grasping the economic opportunities, but also to form mutual networking establishment with stakeholders in the host location.

Acculturation is found as an important source of cross-cultural social and psychological development (Berry, 2010). The human differences in cultural and psychological ecology indicate the patterns of shared ways of living in the society. Life outside of initial socio-cultural habitation also perceived influences by economic, politic and other environmental factors which demand sojourners to accurately acculturate to the new living. Berry's ecocultural framework (Berry, 2010) provides a convincing approach in which situational factors are to be considered for acculturation when sojourners mobilise into the new socio-cultural habitation. The ecocultural framework brings three identifications: (1) ecological and socio-political elements which shaped a contextual underpinning, (2) biological and cultural adaptation elements indicates an adaptation process and (3) psychological outcomes of the acculturation into a cultural phenomenon. 
The ecocultural context provides complex interactions between sojourners and host environment which may cause affection (feeling, emotion and motivation) and interferences. Besides, observing the physical facilities, building and the nature of the host location gives new experiences or psychical challenges to sojourners when it may cause difficulties and dissatisfaction (Dennis and Stroh, 1993; Butler and Hannam, 2014). Lastly, others' behaviour in host location is viewed as complex sets of acculturation when elements are beyond expectation as compared to expected standards. In particular, culture is a dynamic subject to the changes in socioeconomic and political environment. There are some parts of the world (especially in Southeast Asia likes in Malaysia and Indonesia) which are homes for divine, distinct sub-cultures (ethnicities) that have given tonnes of mystification of acculturation among sojourners. For example, the data extracted from The World Bank's website indicated ethnic groups in Indonesia comprise Javanese (45\%), Sundanese (14\%), Madurese (7.5\%), Coastal Malays (7.5\%), others (26\%); in Malaysia made-up Malays and other indigenous groups (Bumiputras) (58\%), Chinese (24\%), persons of Indian descent (8\%), and other groups (10\%) (World Bank, 2015). Thus, Ward (2008) posited sediment to enhance the acculturation understanding and process by incorporating an ethno-cultural identity into the relationship between individuals and host socio-cultural habitation.

\section{MEASURING MULTICULTURAL PERSONALITY AND CROSS-CULTURAL ADJUSTMENT}

\subsection{Sampling Frame}

New Zealand is a chosen destination for data collection as it is featured with the multicultural composition of the society, magnificent natural environment, and socially observed by the authors as the most dreams visited location among Malaysian. Malaysia and New Zealand have two different socio-cultural backgrounds. Statistics on Malaysian population in the New Zealand is limited. However, according to the New Zealand Census on Population and Dwelling Report 2013 (Epnuffic, 2015) there were estimated about 11000 people who said were born in Malaysia and now are residing in the New Zealand either temporarily or permanently. Thus, a purposive sampling technique was adopted in the present study to identify prospective Malaysian sojourners in the New Zealand. The technique perceived relevance as unknown databases to extract exact statistic and sojourners contacts to approach for survey's participation. In line with the study by Mol et al. (2005) usable sojourners' data are identified if meet the characters as follow:

1. Was born outside the New Zealand.

2. Do not hold any permanent resident status or citizenship.

3. Have been sojourning (working and living) in a current location (in the New Zeeland) more than six weeks (a crisis stage, according to the time transition of u-curve culture shock model by Oberg (1960)).

The online survey was employed snowballing technique to solicit the data. The websites of the Malaysia-New Zealand associations (especially students' association across the Universities in the New Zealand) were rolled and the Malaysian embassy was contacted for Malaysian sojourners contact. Invitation emails to participate with the link to the online survey was sent to available email addresses which found on the websites.

\subsection{Instrumentations}

Sojourners' multicultural personality was assessed by the Shortened version of the Multicultural Personality Questionnaire (MPQ-SV). The instrument has tested and accounted for acceptable goodness of fit in measuring expatriates' adaptability (Froese and Peltokorpi, 2011). The present study perceived that a decision to use a shorter version of the scale is reasonable to avoid a social desirable problem and respondent's fatigues in answering a long questionnaire (original MPQ contained 91-items which revised study by Van et al. (2013) posited 40-items). The MPQ measured sojourners' five dimensions of multicultural personality as discussed earlier by five-level Likert scale ranging from 1 (totally not applicable) to 5 (completely applicable) (Van et al., 2013). Sample items for the multicultural personality dimensions are: "tries to understand other people's behaviour" (cultural empathy), "is 
interested in other cultures" (open-mindedness), "makes contacts easily" (social initiative), "radiates calm" (emotional stability), and "changes easily from one activity to another" (flexibility).

A Revised Socio-cultural Adaptation Scale (SCAS-R) (Wilson, 2013) was adopted in the present study as the scale posited psychometrically comprises with an affective element of individual adjustment ability. Affective aspect furnishes addition to the behavioural and cognitive element of acculturative ability among sojourners adjusts into new socio-cultural context as prove by the original Socio-Cultural Adaptation Scale (SCAS) (Ward and Kennedy, 1999). The scale was proved valid and reliable in assessing adjustment ability among sojourners in numerous cultural contexts, especially in Southeast Asia and New Zealand. The 21-items of SCAS-R measured by a five-level Likert scale ranging from 1 (not at all competent) to 5 (extremely competent). Sample items are: "building and maintaining relationships" and "managing my academic/work responsibility".

\section{FINDINGS}

Notably, the online survey system used in this study has showed there were 409 visitors have viewed the survey (obviously located in the New Zealand through IP address indicated). However, 131 visitors did not answer the survey at all and 51 responses discarded as accounted for more than $30 \%$ missing value. Hence, 227 usable responses found genuinely are Malaysian sojourners in the New Zealand that yield 55.5\% of response rate. The result showed $48 \%$ were female, $30.8 \%$ age between 30 to $39,46.3 \%$ were married, $42.3 \%$ were Muslim and $24.7 \%$ were international students (the rest claimed as expatriate, expatriate's spouse, international student's spouse and family, and immigrants). Surprisingly $83.7 \%$ claimed never attended any cultural training before sojourning but claimed to have sufficient previous overseas experiences (probably as tourist).

Initial internal reliability analysis showed an overall shortened version of MPQ is computed with acceptable reliability 0.878 (more than cutoff values of 0.07) (Igbaria et al., 1994). However, individual dimensions' reliability indicated the flexibility is far below cutoff point and discarded. The Cronbach's $\alpha$ of the other four scales (cultural empathy, open-mindedness, social initiative and emotional stability) was found to range $0.70-0.79$. Besides SCAS$\mathrm{R}$ was found highly reliable at 0.91 , treated as a single measure. The correlation test was performed and their means, standard deviations and inter-correlations among the variables presented as in the Table 1 . The result shows all four multicultural personality traits are correlated with socio-cultural adjustment. Among others, the more people took the initiative socialize with local, the more adjust sojourners into his/her new social environment $(r=0.43, \mathrm{p}<0.01)$.

Table-1. Matrix of inter-correlation between the variables.

\begin{tabular}{l}
\hline \\
\hline
\end{tabular}

The result of the regression analysis (Table 2) shows the multicultural personality traits are explained $20 \%$ of the variance which were a statistically significantly contributed to the cross-cultural adjustment $(F=13.75, \mathrm{p}<0.01)$. Predominately, social initiative trait stood significantly in sojourners' cross-cultural adjustment $(\beta=0.34, p<0.05)$. 
Table-2. Simultaneous Regression Coefficients ${ }^{\mathrm{a}}$.

\begin{tabular}{|c|c|c|c|}
\hline \multirow[b]{2}{*}{ Model } & Standardized Coefficients & \multirow[b]{2}{*}{$\mathbf{t}$} & \multirow[b]{2}{*}{ Sig. } \\
\hline & $\boldsymbol{\beta}$ & & \\
\hline MPQ_CultureEmpathy & -0.11 & $-1.36 *$ & 0.18 \\
\hline MPQ_OpenMindedness & 0.12 & $1.48 *$ & 0.14 \\
\hline MPQ_SocialInitiative & 0.34 & $4.30 * *$ & 0.00 \\
\hline MPQ_EmotionalStability & 0.12 & $1.57 *$ & 0.12 \\
\hline
\end{tabular}

a. Dependent Variable: SCAS-R

**. $\alpha$ is significant at the 0.05 level $(\mathrm{t}>1.65)$.

*. $\alpha$ is significant at the 0.10 level $(t>1.28)$.

\section{DISCUSSION}

\subsection{Multicultural Personality}

The present study applied sojourners' different ecological perspective to better understand cross-cultural adjustment abroad. An appropriate multicultural personality argued as important aspects for effective adaptation and cross-cultural adjustment. Ability to adjust to a new environment is supported by sufficient social learning and adaptation effort (Sam and Berry, 2010) is essential to find an intercultural connectedness between home and host socio-cultural habitation (Berry, 2002). Notably, cultural empathy, open-mindedness, social initiative and emotional stability are four multicultural personality traits which support sojourners to acculturate with different socio-cultural habitation.

The result of the present study and prior studies (refers, (Terracciano et al., 2003; Bhaskar-Shrinivas et al., 2005; Mol et al., 2005; Lee and Sukoco, 2007; Froese and Peltokorpi, 2011; Shaffer et al., 2012)) identified the capacity of personal characters explain how people act the way they do. Personality is an adaptive mechanism that allows a person to attain his/her international mobility goals (Froese and Peltokorpi, 2011). The most important personal character of social initiative has given implication that a person needs to take some movements to reduce international mobility tensions by closing the socio-cultural gap encountered. Adjusting social living expectation in host location is established by taking initiative to find the alternative ways of doing things differently from home. Social difficulties as discussed by scholars (example, (Bhaskar-Shrinivas et al., 2005; Ward, 2008; Lauring and Selmer, 2010; Froese, 2012; Harvey et al., 2012)) caused by unawareness on host country's cultural composition and Inability to make appropriate social adaptations. Highlighted, understanding of cultural components builds consciousness to the cultural differences. In particular, having the appropriate social initiative to obtain social support from the others in the host country is able to eliminate strange, isolated, lonely, discriminate, separate or depression while sojourning abroad (especially as a solo traveller).

In addition, to give additional support to previous studies especially in multicultural personality such as (Ward and Kennedy, 1999; Terracciano et al., 2003; Mol et al., 2005; Lee and Sukoco, 2007; Froese and Peltokorpi, 2011) multicultural personality traits of emotional stability, open-mindedness and cultural empathy are perceived contribute to the sojourners' effective cross-cultural adjustment abroad. Feeling of homesickness, helpless or marginalised may rise, especially among those who are from a high-contact culture (Torbiorn, 1985). A discriminate feeling among sojourners worries may affect their work performance and goal accomplishment. Adequate psychological or mental health is vital when addressing socio-cultural difficulties. Thus, sufficient emotional stability will help suppress the emotion appropriately under stressful circumstances.

To ensure local acceptance, sojourners need to discard a personal and social block by giving respect toward local traditions and willing to involve with social events in the host country. The unrestricted thought of open-mindedness is important to eliminate false socio-cultural sentiments of ethnocentrism, racism or stereotyping (Froese and Peltokorpi, 2011; Van et al., 2013). With appropriate open-mindedness, it gives memorable experiences while sojourning abroad. For example, bar and lounge is synonymous with alcohol among Malaysian Muslim Malays. 
Alcohol is prohibited by religion of Islam. Thus, due to social compression in Malaysia, considered taboo among the Malays to visit bars or lounge. However, in New Zealand it is a social norm among young adults to have a social gathering after work especially Friday afternoon. Pleasing friends for beneficial contact with locals, juice or tap water is an option for alcohol.

In addition, significant cultural empathy perceived support adjustment and adaptation into the new environment. To avoid annoyance feeling or frustration with locals, sojourners should be able to show an interest in local culture, willing to adjust, being aware and sensitive to socially clues (attitude, belief, norm and value), and show respect to the others. The knowledge about the needs and expectation of others is important to obtain a beneficial social relationship. From one's own point of view, how we interpret socio-cultural encounter as relevant or irrelevant helps to determine capability adapt to different environments (Mol et al., 2005). Reflecting self social norms and values with the others, helps to disclose the relatedness which increase the effectiveness of intercultural message transmission.

Being flexible means able to align new mindset in the new socio-cultural location. Replacing prior philosophy by accepting new perspective does not always relevant, especially among the collective cultures in Malaysia. Religions and other traditional beliefs, norms and values play a significant role, among Malaysian especially the Malays. For example, not performing prayer due to unavailable the Qibla sign or abolution tap in the washroom; drinking alcohol; consume ham or gambling while sojourning abroad are not considered as social flexibility but religious-based social obligation. Due to that reason, the present study believes the flexibility traits are perceived as unreliable characters to the cross-cultural adjustment.

\subsection{Research Limitations}

Different sojourner may record different experiences and social-cultural encounters depending on their mission, goals, length, financial support, experiences and location in the host location. Thus, this background aspect should be controlled but not treated in the present study. Heterogeneity factor should be taken into consideration in the future study. Different locations may offer different forms of facilities, hardiness, sceneries or attitudinal influences from the locals. Political, economic and social environments are varied from a location to another; give sojourners different experience and knowledge. Thus, the generalisation of issues from the present study could be limited. The results are possibly relevant to other sojourners with similar background and sojourning experience at similar setting in New Zealand, but it is quite difficult to extend the findings to other developed countries with different social systems. The climate change and dynamic nature of a country's economic and political systems could read the subjectivity of the findings for current socio-cultural habitation. Nonetheless, the present study could enrich the understanding the social mobility among sojourners and elements to support cross-cultural adjustment.

\subsection{Research Implications}

There are both empirical and theoretical implications of the findings obtained in the present study for future knowledge enhancement. Illustrated earlier, cultural variation between distinct group members has caused international mobility difficulties, anxiety, frustration or uncertainty. The inability to make necessary adjustment and adaptation is the result of sojourning failure, unsatisfactory performance, social breakdown and even family conflict. Understanding the implicit context of the host's culture is equally important in adjusting to explicit appearances.

Empirically, the result of the present study provides additional support to prior study (Ward and Kennedy, 1999; Froese and Peltokorpi, 2011; Wilson, 2013) on the use of shortened version of MPQ (MPQ-SV) and revised version of SCAS (SCAS-R). Particularly, it was found that the social initiative is a vital personal trait may give additional value to local enquiry on ethnic diversity; connectivity among multicultural society especially in Southeast Asia's socio-cultural setting. For those organizations who plan in sending off staff and sojourners abroad, it is important to incorporate precise elements of multicultural personality in their pre-departure training. Besides, the present study has 
proven that, by giving them greater exposure of the outer section of the initial socio-cultural habitation, it would help assist in widening their cultural horizons and understanding.

Theoretically, the present study also aids in giving additional understanding of the international mobility research by highlighting the importance of multicultural personality, especially social initiative trait on sojourners' crosscultural adjustment. The personality was found to be able to strengthen habitual and ecological processes (Berry, 2002; 2010; Sam and Berry, 2010) and ascertain adaptation and cross-cultural adjustment (Ward and Kennedy, 1999; Ward, 2008; Froese and Peltokorpi, 2011). Tapping cultural issues on socio-cultural variation seems important in connection with moral consequences, which are blended with religious perspectives, etiquette and social manners. Therefore, sojourner's who is successfully acculturate with others who culturally different create a harmonious interpersonal relationship and reduce social conflict and difficulty. The research implication of the present study possibly augments the importance of sojourners' social quality and ability to appropriately adjust and adapt to the different socio-cultural habitation.

\section{CONCLUSION}

The present study reflects on how a sojourner who was tightened with their initial socio-cultural habitation may experience socio-living difficulties and inability while sojourning abroad. Notably, the cultural variations have reduced the sojourner's excitement when encountering socio-cultural difficulties (physically, psychologically and behaviourally) in another country. However, the appropriate transition and adjustment processes have facilitated the sojourner to successfully acculturate and create a memorable adaptation. Moreover, an affective, cognitive and behavioural affirmation has helped in reducing inappropriate socio-cultural sentiments which are crucial in strengthening the socio-cultural integration abroad. To highlight, social initiative is proven as the most important sojourner's multicultural personality to have effective cross-cultural adjustment abroad. To quote one of the respondents' in the present study remarks: “The more you learn about other cultures and way of life in another country; the more you understand about yourself".

Funding: Writing this paper and attending conference are funded by the UiTM Sarawak's research excellent fund [ref: 600-RMU/DANA 5/3 (1/2015)].

Competing Interests: The authors declare that they have no competing interests.

Contributors/Acknowledgement: All authors contributed equally to the conception and design of the study.

\section{REFERENCES}

Berry, J.W., 2002. Cross-cultural psychology: Research and applications. Cambridge University Press.

Berry, J.W., 2010. Intercultural relations and acculturation in the Pacific region. Journal of Pacific Rim Psychology, 4(02): 95-102.

Bhaskar-Shrinivas, P., D.A. Harrison, M.A. Shaffer and D.M. Luk, 2005. Input-based and time-based models of international adjustment: Meta-analytic evidence and theoretical extensions. Academy of Management Journal, 48(2): 257-281.

Butler, G. and K. Hannam, 2014. Performing expatriate mobilities in Kuala Lumpur. Mobilities, 9(1): 1-20.

Dennis, L.E. and L.K. Stroh, 1993. Take this job and. International Journal of Organizational Analysis (1993 - 2002), 1(1): 85.

Epnuffic, 2015. Retrieved from https://www.epnuffic.nl/en/internationalisation/mobility-statistics/international-context/globalmobility-flows [Accessed 18th December 2015].

Freeman, S. and S. Lindsay, 2012. The effect of ethnic diversity on expatriate managers in their host country. International Business Review, 21(2): 253-268.

Friedman, P.A., 2007. Making sense of nonsense in Hong Kong. Paper Presented at the 4th Annual Sprott Doctoral Symposium.

Friedman, P.A., L.S. Dyke and S.A. Murphy, 2009. Expatriate adjustment from the inside out: An auto ethnographic account. International Journal of Human Resource Management, 20(2): 252-268.

Froese, F.J., 2012. Motivation and adjustment of self-initiated expatriates: The case of expatriate academics in South Korea. International Journal of Human Resource Management, 23(6): 1095-1112. 
Froese, F.J. and V. Peltokorpi, 2011. Cultural distance and expatriate job satisfaction. International Journal of Intercultural Relations, 35(1): 49-60.

Guyton, E.M. and M.V. Wesche, 2005. The multicultural efficacy scale: Development, item selection, and reliability. Multicultural Perspectives, 7(4): 21-29.

Harvey, M., N. Mcintyre, M. Moeller and H. Sloan, 2012. Managerial self-concept in a global context an integral component of cross-cultural competencies. Journal of Leadership \& Organizational Studies, 19(1): 115-125.

Igbaria, M., S. Parasuraman and M.K. Badawy, 1994. Work experiences, job involvement, and quality of work life among information systems personnel. MIS Quarterly, 18(2): 175-201.

Lauring, J. and J. Selmer, 2010. The supportive expatriate spouse: An ethnographic study of spouse involvement in expatriate careers. International Business Review, 19(1): 59-69.

Lee, L. and B. Sukoco, 2007. The effects of expatriate personality and cultural intelligence on the expatriate adjustment: The moderating role of expatriate. Paper Presented at the 13th Asia Pacific Management Conference.

Mol, S.T., M.P. Born, M.E. Willemsen and H.T.V.D. Molen, 2005. Predicting expatriate job performance for selection purposes: A quantitative review. Journal of Cross-Cultural Psychology, 36(5): 590-620.

Oberg, K., 1960. Culture shock: Adjustments to new cultural environments. Practical Anthropology, 4: 177-182.

Sam, D.L. and J.W. Berry, 2010. Acculturation when individuals and groups of different cultural backgrounds meet. Perspectives on Psychological Science, 5(4): 472-481.

Searle, W. and C. Ward, 1990. The prediction of psychological and sociocultural adjustment during cross-cultural transitions. International Journal of Intercultural Relations, 14(4): 449-464.

Shaffer, M.A., M.L. Kraimer, Y.-P. Chen and M.C. Bolino, 2012. Choices, challenges, and career consequences of global work experiences a review and future agenda. Journal of Management, 38(4): 1282-1327.

Terracciano, A., R.R. McCrae, D. Hagemann and J.P.T. Costa, 2003. Individual difference variables, affective differentiation, and the structures of affect. Journal of Personality, 71(5): 669-704.

Torbiorn, I., 1985. The structure of managerial roles in cross-cultural settings. International Studies of Management \& Organization, 15(1): 52-74.

Van, D.Z.K., O.J.P. Van, J.G. Ponterotto and A.W. Fietzer, 2013. Multicultural personality questionnaire: Development of a short form. Journal of Personality Assessment, 95(1): 118-124.

Ward, C., 2008. Thinking outside the Berry boxes: New perspectives on identity, acculturation and intercultural relations. International Journal of Intercultural Relations, 32(2): 105-114.

Ward, C. and A. Kennedy, 1999. The measurement of sociocultural adaptation. International Journal of Intercultural Relations, 23(4): 659-677.

Wilson, J., 2013. Exploring the past, present and future of cultural competency research: The revision and expansion of the sociocultural adaptation construct. Unpublished Doctoral Dissertation. Victoria University of Wellington.

World Bank, 2015. Retrieved from http://data.worldbank.org/indicator/SP.POP.TOTL [Accessed 21st December 2015]. 